\section{Lamarckian Proteins}

CRICK $^{1}$ once stated explicitly that the stability of the nucleic acid molecule ruled out the possibility that acquired characteristics might be hereditary-molecular biologists, in spite of a curiously detached attitude toward the philosophy of biology, have generally tended to support Weismann and to reject the views of Lamarck and Darwin concerning the effects of the environment on heredity.

But it has become increasingly apparent that the inheritance of acquired characters must be considered seriously ${ }^{2}$, and Koshland ${ }^{3}$, at the Atlantic City meeting of the Federated Societies, presented evidence acceptable to physical chemists proving that enzyme action depends on the alteration of the conformation of a flexible polypeptide chain of the enzyme by the substrate-a revelation which makes it essential to reintroduce Lamarckian concepts into molecular biology along the lines originally suggested by Pauling 4 and recently exploited by Lindegren $^{5}$ in speculations on the origin of life and the mechanism of gene action. If the conformation of an enzymeprotein can be controlled by a substrate, then the conformation of one protein can be controlled by the structure of an associated protein. Therefore, a change produced. by an environmental effect on the structure of a proteinaceous organelle in one generation (by heat denaturation or by the oxidation of sulphydril groups) would be transmitted to the daughter organelles in the succeeding generation, if (as Koshland's theory suggests) the structure of the proteins already assembled into the organelle controlled the conformation of the protein molecules subsequently added to the organelle.

The only protein-containing organelles which could be exempted from transmissible environmental hereditary effects would be those which wero completely disassombled at each generation. 'The abolition of most Dauermodifikationen by sexual reproduction ${ }^{6}$, but not by vegetative reproduction, suggests that the components of most organelles responsible for the transmission of acquired hereditary characters are disassembled when gametes are formed, but also implies that some sex cells transmit some altered daughter organelles in an altered condition to the next generation.

Yeast genetics has supplied many examples of genes which respond mutagenically and specifically to the effects of substrate $e^{7,8}$, but the facts have generally been discounted in the absence of a theory to justify their acceptance. Now that Koshland has demonstrated an acceptable mechanism, it is possible to give credence to those reports which stipulate that a carbohydrate substrate may direct the mutation of a gene controlling the production of an enzyme capable of hydrolysing that specific substrate. My receptor ${ }^{9,10}$ hypothesis assumes that the receptor (homologous to the activator of McClintock $^{11}$ and the operator of Jacob and Monod ${ }^{12}$ ) is a heritable and mutable protein resembling the enzyme controlled by the gene. Koshland's communication at Atlantic City was followed by another in which Monod ${ }^{13}$ proposed that one component of the gene is a plastic protein, thus bringing the receptor and the operon-hypothesis into closer agreement.

Pirie $^{14}$ has suggested that biopoiesis might have involved an early polyphyletic phase of long duration in which organic substances played only a minor part while inorganic catalysts were of primary importance. His view has been supported by Abelson's ${ }^{15}$ evidence indicating that the original probiotic milieu was probably poor in amino-acids. It seems possible that primitive forms based on inorganic catalysts might have incidentally synthosized a pool of amino-acids.

Fox's ${ }^{16}$ experiments indicate that proteins might have arisen spontaneously in such a pool simply by exposing the mixture to heat. Subsequent to the accumulation of a protein-pool, a protein-based biopoiesis might have developed in which the catalysts were primarily polypeptide chains, and in which adaptability, hereditary stability and mutability depended on a folding process like that suggested by Pauling and demonstrated by Koshland. But one might suppose that the proteinbased bionts were exceptionally sensitive to environmental effects and, hence, exceptionally unstable.

The development of a more stable living state based on nucleic acid must have followed rather than preceded the protein-based system, because of the fantastic require. ments for proteinaceous enzymes which are imposed on an organism for the implementation of nucleic acid syntheses. The most primitive nucleic acid-bionts would have possessed two important advantages over (and would readily have replaced) even the most advanced protein-based competitors, first, because the reproductive systems of nucleic acid-based bionts are so much more stable and, secondly because nucleic acid-bascd systems are able to store capacities to synthesize adaptive enzymes in the form of 'self-reproducing' nucleotide sequences over long periods during which these capacities are not used.

This work was supported by a research grant from the U.S. Public Health Service $C A$ 04682-04.

\section{Cart C. Lindegren}

Biological Research Laboratory,

Southern Tllinois Univorsity, Carbondale.

${ }^{1}$ Crick, F. H. C., Abst. Symp. Growth; Molecule, Cell, and Organism, 7 (Purdue University, Lafayette, Ind., 1060).

${ }^{2}$ Lindegren, C. C., Bull. Res. Counc. Israel (in the press).

'Koshland, D. E., Forty-seventh Ann. Meeting Fed. Amer. Soc. Exp. Biot., Atlantic City, N.J. (1963).

${ }^{4}$ Pauling, L., J. Amer. Chem. Soc., 62, 2643 (1940).

${ }^{5}$ Lindegren, C. C., Nature, 189, 959 (1961).

- Jollos, V., Arehiv fur Protistenkunde, 83, 197 (1934).

${ }^{7}$ Lindegren, C. C., and Pittman, D., J. Gen. Micro., 9, 494 (1953).

${ }^{8}$ Tindegren, C. C., and Pittman, J. D., Nature, 182, 271 (1958).

${ }^{9}$ Lindegren, C. C., Experientia, 9, 75 (1953).

${ }^{10}$ Lindegren, C. C., J. Theoret. Biol. (in the press).

${ }^{11}$ McClintock, B., Amer. Nat., 95, 265 (1961).

${ }^{12} \mathrm{Jacob}, \mathrm{F}$, and Monod, J., C.R. Acad. Sci., Paris, 249, 1282 (1959).

${ }_{13}$ Monod, J. I., Forty-seventh Arn. Meeling Fed. Amer. Sor. Exp. Biol., Atlantic City, N.J. (1963).

14 Pirie, N. W., Ann. N.Y. Acad. Sci., 69, 369 (1957). ${ }^{15}$ Abelson, P. H., Symp. The Living State, Western Reserve University,
University IIospitals of Cleveland, Ohio (1962).

${ }^{16}$ Fox, S. W., Ann. Meet. Amer. Assor. Adv. Sci., Chicago (1959).

\section{Electronic Delocalization and Biochemical Evolution}

IN a stimulating article in Nature Pullman and Pullman ${ }^{1}$ direct attention to the fact that many essential biomolecules contain resonance systems with delocalized $\pi$-electrons. The authors are right in stressing their importance for the function of these molecules in life processes; but the authors" claim that this is "one essential, although apparently hitherto unnoticed aspect of biochemistry" cannot bo accepted. I am convineed that many biochemists are already quite familiar with it.

Apart from discussions on its importance for the biological role of pyrrole pigments ${ }^{2-5} \mathrm{~T}$ have discussed it in a wider frame with reference to polyenes, isoalloxazines, pterins, nicotinamide coenzymes, pyrrole and indole derivatives and metal chelates, in a lecture of mine introducing a symposium on "Animal Pigments" at the 1939 meeting of the Australian and New Zealand Association for the Advancement of Scionce 6 . Later.5, I called the biomolecules with essential biological functions 'ergons'they are not all catalysts-in order to differentiate them from life's fuel substances and building materials. My concopt was thus somewhat narrower than that of the authors; it did not, for example, include proteins and nucleic acids.

To the long list of functions given by the authors in which delocalized $\pi$-electrons play important parts one 